\title{
Violência conjugal lésbica: relatos de assistentes sociais que atendem mulheres na cidade de Niterói
}

\author{
Lesbian marital violence: reports of social \\ workers attending women in the city of Niterói
}

\author{
Nathaliê Cristo Ribeiro dos Santos ${ }^{a}$ \\ (D) https://orcid.org/0000-0002-8497-3111 \\ Rita Freitas ${ }^{a}$ \\ (D) https://orcid.org/0000-0001-8251-9997 \\ Glauber Lucas Ceara-Silva ${ }^{a}$ \\ (D) https://orcid.org/0000-0002-3614-0262
}

Resumo: A violência contra as mulheres é fenômeno recorrente no contexto brasileiro e pode perpassar qualquer tipo de conjugalidade. Nesse sentido, este artigo aborda o tema da violência nas conjugalidades lésbicas e apresenta uma análise dos relatos de assistentes sociais que atendem mulheres em situação de violência na cidade de Niterói (RJ), a fim de verificar como a violência conjugal lésbica tem aparecido em seus cotidianos profissionais.

Palavras-chave: Violência. Mulheres. Lesbianidade.

\begin{abstract}
Violence against women is a recurring phenomenon in the Brazilian context and can permeate any type of conjugality. In this sense, this article approaches the theme of violence in lesbian conjugalities, and presents an analysis of the reports of social workers attending women in a situation of violence in the city of Niterói, RJ, in order to verify of these professionals, how lesbian conjugal violence appears in their work actions.
\end{abstract}

Keywords: Violence. Women. Lesbianity. 


\section{Introdução}

violência contra as mulheres é um fenômeno mundial e nacional. Os
dados do balanço realizado pela Central de Atendimento à Mulher
(Ligue 180) relatam que só no primeiro semestre de 2016 houve 67.962 casos de violência atendidos. Durante muito tempo a violência dirigida às mulheres se manteve como um assunto relacionado ao âmbito privado, $\mathrm{e}$ foi preciso uma longa trajetória de reivindicações dos movimentos feministas e de mulheres para que essa questão se tornasse alvo de políticas sociais. As ações desses movimentos possibilitaram a criação de aparatos institucionais e estatais para combater essa problemática. No âmbito mundial, as conferências e convenções internacionais ${ }^{1}$ sobre os direitos humanos das mulheres possuem um papel fundamental no reconhecimento da cidadania deste grupo específico.

No Brasil, é imprescindível destacar a Lei n. 11.340/2006, popularmente conhecida como Lei Maria da Penha, que representa um grande avanço no enfrentamento da violência doméstica, na medida em que é a primeira legislação a tratar especificamente da violência de gênero e responsável por criar "mecanismos para coibir e prevenir a violência doméstica e familiar contra a mulher" (Brasil, 2006). ${ }^{2}$

Destacam-se também as Conferências Nacionais de Políticas para as Mulheres (2004, 2007, 2013, 2016), nas quais foram criados os planos nacionais. Todo esse processo deu base para que surgisse, em 2011, a Política Nacional de Enfrentamento à Violência contra a Mulher, a partir da Secretaria Especial de Políticas para as Mulheres da Presidência da República, ${ }^{3}$ que se torna um marco no enfrentamento da violência de gênero, na medida em que:

Ver Corrêa (2009).

2 Da mesma forma, é importante destacar a Lei n. 13.104, de 9/3/2015, que inclui o feminicídio (assassinato de mulheres em função de sua condição de mulheres) como circunstância qualificadora de crime hediondo.

3 A Secretaria Especial de Políticas para as mulheres da Presidência da República foi criada em 2003, durante o governo do ex-presidente Luiz Inácio Lula da Silva. Entretanto, no ano de 2016, a Medida Provisória n 726, de 12/5/2016, estabeleceu a extinção do Ministério das Mulheres e realizou a junção da Secretaria de Políticas de Promoção da Igualdade Racial 
Estabeleceu conceitos, princípios, diretrizes e ações de prevenção e combate à violência contra as mulheres, assim como de assistência e garantia de direitos às mulheres em situação de violência, conforme normas e instrumentos internacionais de direitos humanos. (Brasil, 2011, p. 9)

A partir desta política é construída a rede de enfrentamento à violência contra as mulheres (envolvendo organizações governamentais e não governamentais), bem como a Rede de Atendimento à Mulheres em Situação de Violência, oferecendo serviços nas áreas de saúde, direito, assistência social, psicologia, dentre outras. ${ }^{4}$

Feito este breve relato, é importante enfatizar que a violência conjugal é multifacetada. A categoria mulheres possui em seu interior identidades múltiplas e diversas. Em outras palavras, a violência conjugal atinge mulheres brancas e negras, ricas e pobres, heterossexuais, transexuais, bissexuais e lésbicas. Nesse sentido, este artigo pretende analisar, mesmo que de forma introdutória, a existência de uma violência específica e ainda invisibilizada: a violência nas conjugalidades lésbicas. Apesar de ser um assunto ainda pouco abordado no montante de estudos sobre a violência contra as mulheres, trata-se de uma problemática que merece atenção e reflexão. Acreditamos que a grande maioria das análises sobre violência contra a mulher mantém um recorte focado no universo conjugal heterossexual, muitas vezes deixando passar outras expressões igualmente graves, como é o caso da violência conjugal lésbica.

Diante disso, este trabalho consiste em um esforço de compreender como a rede de atendimento às mulheres em situação da violência, em Niterói, tem enfrentado o problema nas conjugalidades lésbicas. A intenção é verificar como essa questão tem aparecido nos cotidianos de trabalho dos profissionais e investigar se as lésbicas envolvidas em violência conjugal e doméstica têm procurado ajuda profissional, e se sim, como tem sido esse atendimento e quais são as concepções profissionais acerca desse tipo

(Seppir), Secretaria de Políticas para as Mulheres (SPM), Secretaria de Direitos Humanos (SDH) e Secretaria Nacional de Juventude (SNJ).

4 Para um maior conhecimento dessas redes e das instituições que a compõem, ver SPM (2011). 
específico de violência. É nesse sentido que foi realizada uma pesquisa de campo em três instituições da rede de atendimento de Niterói: o Centro Especializado em Atendimento à Mulher (Ceam), que é um serviço da Coordenadoria de Políticas e Direitos das Mulheres de Niterói (Codim); o Programa SOS Mulher, do Hospital Universitário Antônio Pedro e o Centro de Cidadania LGBT de Niterói.

A primeira parte deste artigo aborda algumas particularidades da violência conjugal entre lésbicas, além de sinalizar para a dupla discriminação que mulheres lésbicas em situação de violência têm enfrentado. Já a segunda parte busca apresentar os resultados da pesquisa de campo.

\section{Particularidades da violência conjugal lésbica}

A violência doméstica e conjugal é um problema que tem atingido inúmeras mulheres. Apesar de em sua grande maioria atingir mulheres heterossexuais, se pararmos para analisar esse problema de forma mais aprofundada veremos que a violência dirigida às mulheres tem perpassado diversos tipos de relação conjugal, e não só a heterossexual. Grossi (2000, p. 304) destaca que:

A violência doméstica é resultado de complexas relações afetivas e emocionais, não restritas ao âmbito da heterossexualidade, podendo também ocorrer em relações afetivas envolvendo duas mulheres ou dois homens.

Ou seja, a complexidade do fenômeno da violência conjugal nos estimula a investigar outros tipos de violência para além do binômio homem-mulher, pois uma análise restrita a essa configuração não congrega as diversas expressões e realidades em que se manifesta a violência contra as mulheres.

Algo que deve ser destacado é que falar de violência conjugal/doméstica entre lésbicas pode gerar a impressão de que a intenção é apontar algo de ruim no que se refere à população lésbica, como se isso indicasse uma "mancha" nas conquistas pleiteadas pelo movimento LGBT. Entretanto, o que se pretende aqui é destacar a existência de uma violência invisibilizada, 
mas que é uma problemática real na vida de muitas mulheres. A partir da constatação de que essa violência existe, é preciso que esse fenômeno seja investigado, devendo-se atentar para o fato de que as lésbicas precisam ser assistidas e amparadas pelas instituições que integram a rede de atendimento a mulheres vítimas de violência, no sentido de que a proteção social da população lésbica seja devidamente efetivada. ${ }^{5}$ Como destaca Santos (2012, p. 7): “Apesar da invisibilidade estatística ou midiática, a violência conjugal lésbica exerce-se de forma tão agressiva quanto qualquer outra forma de violência doméstica".

Dito isso, destacamos que as particularidades dessa violência fazem dela um rico campo de análise acerca do reconhecimento das questões de intimidade, sexualidade, cidadania lésbica e dos direitos das mulheres. Topa afirma que ao mesmo tempo em que se inclui na violência doméstica de forma mais ampla, a violência conjugal lésbica tem aspectos particulares,

decorrentes do estatuto minoritário que as relações entre pessoas do mesmo sexo têm na nossa sociedade, e do fato de as lésbicas serem duplamente discriminadas: por serem mulheres, por serem mulheres no contexto de uma relação lésbica. (Topa, 2010, p. 1)

Santos (2012, p. 6) também afirma que a violência conjugal lésbica possui características específicas, e nesses casos "acrescem fatores especificamente associados à condição lésbica num contexto heteronormativo e lesbofóbico dominante". Dentre os estudos acerca da violência conjugal lésbica, existem diferentes tendências e vertentes explicativas. Uma dessas tendências tem procurado analisar a questão a partir de uma abordagem focada nos aspectos psicológicos que envolvem essas agressões. Há também uma interpretação dessa violência como sendo composta de agressões recíprocas entre as parceiras. E também pode ser encontrada dentre as produções acadêmicas nessa área uma teoria que interpreta a violência conjugal entre lésbicas enquanto uma reprodução da violência envolvendo um

A própria Lei Maria da Penha, em seus artigos $2^{\circ}$ e $5^{\circ}$, atesta que abrange mulheres, independentemente de sua orientação sexual. 
homem e uma mulher. Gostaríamos de abrir um parêntese aqui para tecer uma breve crítica a essa última tendência, pois ela acaba por cair em uma análise reducionista e restrita ao binômio homem-agressor, mulher-vítima. Ou seja, quando se defende que em um relacionamento lésbico a mulher que possui uma performance mais masculinizada é sempre aquela que efetua a agressão, desconsidera-se a complexidade da violência nas relações conjugais, deixando de lado o fato de que esses papéis de agressor(a) e vítima não são tão fechados e estáticos. ${ }^{6}$

Como destaca Topa (2010), falar de violência conjugal nas relações lésbicas implica questionar as tradicionais concepções e formas de relacionamento conjugal entre mulheres, concepções essas que perpetuam estereótipos veiculados através do modelo heteronormativo (butch vs. femme, por exemplo), e assinalar um comportamento “impensável” em relações tidas como mais simétricas e igualitárias em termos de poder.

Dito isso, algo que consideramos importante apontar é que ao analisar a questão da violência conjugal lésbica surge a necessidade de compreender a violência enquanto uma tentativa de um indivíduo estabelecer poder sobre outro. Ou seja, "mesmo quando duas pessoas são do mesmo gênero, diferenças de poder existem e podem ser usadas como mecanismos para controlar o parceiro" (Avena, 2010, p. 102) É importante compreender a violência enquanto um jogo de poder, em que um indivíduo deseja exercer poder sobre outro por meio da violência física, psicológica, sexual, dentre outras. Como destaca Avena (2010, p. 5), "a violência de um ponto de vista feminista é definida como a tradução do controle e do poder exercido sobre alguém”.

Outra questão importante com relação à realidade das lésbicas em situação de violência é o "duplo armário" em que estão inseridas (Santos, 2012; Topa, 2010; Vickers, 1996). A maioria das pessoas LGBTs,7 em determinado momento da vida delas, se veem diante de um dilema: revelar ou não sua orientação sexual ou sua identidade de gênero para as pessoas de

6 Cf. também Santos (2012).

7 Referindo-se a lésbicas, gays, bissexuais, transexuais. Em 2008, a partir da Conferência Nacional GLBT, aprovou-se o uso da sigla LGBT para a denominação do movimento, dada a necessidade de aumentar a visibilidade do segmento das lésbicas. 
seu convívio. Essa atitude ficou conhecida popularmente como o ato de "sair do armário". Esse é um "divisor de águas" na trajetória de toda pessoa homossexual e um desafio na construção de sua identidade.

A "saída do armário" torna-se um evento traumático em muitos casos, pelo fato de os familiares condenarem a orientação sexual da pessoa, muitas vezes agredindo-a física e/ou verbalmente, ou até mesmo expulsando-a de casa. O "duplo armário" consiste na compreensão de que além do armário que as lésbicas enfrentam por conta da discriminação contra as pessoas LGBTs, acrescenta-se a esse um "segundo armário" relacionado ao próprio fato de sofrer a violência doméstica.

No contexto brasileiro, em situações de violência doméstica, há muitas vezes uma cultura de culpabilização das mulheres agredidas por seus(suas) parceiros(as). Essa "cultura" faz com que muitas mulheres prefiram manter essa violência em silêncio, configurando assim uma espécie de "armário" em torno da revelação da agressão sofrida. Com relação à violência entre lésbicas, então, ocorre um "duplo armário" e também uma "dupla discriminação" (Santos, 2012), resultando em um processo no qual ocorre "a discriminação que se manifesta pela homofobia e condenação da homossexualidade, por um lado, e o segredo a que as situações de violência são votadas, por outro" (Topa, 2010, p. 14).

Nesse sentido, essa situação faz com que a maioria das lésbicas em situação de violência opte por enfrentar as agressões de maneira isolada e silenciada. No caso das lésbicas vítimas de violência conjugal, as intersecções entre gênero e orientação sexual podem gerar uma intensificação da violência sofrida, pelo fato de sua orientação sexual não ser respeitada e aceita como legítima. Avena (2010) destaca que "este assunto é um tanto indigesto para muitas mulheres, pois esta violência pode deixar marcas ainda mais profundas que a violência masculina, na medida em que suas vítimas não têm a quem recorrer nos suportes do apoio externo - familiares, ou instituições" e afirma que muitas mulheres lésbicas "que procuraram apoio em delegacias da mulher tiveram que encarar uma segunda violência, além da já sofrida: a violência do preconceito contra a homossexualidade" (Avena, 2010, p. 2). 
Nesse sentido, alguns autores têm trabalhado com o conceito de "tolerância institucional": "o conjunto de valores, imaginários, comportamentos, atitudes e práticas racistas e sexistas reproduzidas nas instituições do Estado a partir da atuação de seus servidor@s, favorecendo e perpetuando a violência contra as mulheres" (CFEMEA, 2014, p. 11). Ao adotar esse conceito, a ideia é "abordar as diferentes gradações da violência institucional experimentadas pelas mulheres que recorrem aos serviços do Estado e que são revitimizadas pela atuação discriminatória dessas instituições" (Idem, s/p).

\section{A pesquisa de campo: o que os profissionais da rede de atendimento relatam acerca da violência conjugal lésbica?}

Niterói é um município do estado do Rio de Janeiro que conta com uma rede relativamente ampla de atendimento à violência contra a mulher, apresentando-se assim como um vasto campo de análise sobre as questões relacionadas a essa temática. ${ }^{9} \mathrm{Na}$ área dos movimentos LGBT, a cidade tem protagonismo, sendo hoje a única no estado do Rio a possuir um Conselho Municipal LGBT.

Outro fator que estimulou a realização dessa pesquisa no âmbito municipal é que Niterói apresenta dados alarmantes com relação à violência contra as mulheres. De acordo com dados do Dossiê Mulher (2015), todos os dias ao menos duas mulheres são vítimas de algum tipo de violência no município.

Entendemos que a pesquisa qualitativa permite um aprofundamento na realidade e na subjetividade do tema estudado. Por isso optamos

8 Esse conceito é originário de pesquisa do Projeto Interagencial da Colômbia, revisto e adaptado à realidade brasileira pelo Centro Feminista de Estudos e Assessoria (CFEMEA) e o Instituto de Pesquisas econômicas Aplicadas (Ipea).

9 Esta rede tem como principais instituições a Delegacia Especializada de Atendimento à Mulher (Deam), que data de 1986; a Coordenadoria de Políticas e Direitos das mulheres (Codim), criada em 2003, com o intuito de estimular a construção de políticas que ratifiquem a cidadania e os direitos da mulher; o Centro Especializado de Atendimento à Mulher em situação de Violência (Ceam), que é um serviço proporcionado pela Codim; o Programa SOS Mulher/Huap, que teve início em 2002, além do Juizado da Violência Doméstica e Familiar Contra a Mulher, entre outros serviços. 
metodologicamente por trabalhar com a história oral, no sentido de resgatar as falas dos sujeitos envolvidos nesse processo. Assim, realizamos entrevistas semiestruturadas com assistentes sociais das seguintes instituições: Centro Especializado em Atendimento à Mulher, vinculado à Coordenadoria de Políticas e Direitos das Mulheres, e o Programa SOS Mulher, vinculado ao Hospital Universitário Antônio Pedro. Optamos também por ouvir o Centro de Cidadania LGBT de Niterói. ${ }^{10}$ Esses serviços foram escolhidos porque são importantes portas de entrada para mulheres em situação de violência na cidade.

Um dos objetivos específicos dessa pesquisa consistiu em analisar e verificar se os profissionais que atendem mulheres em situação de violência têm recebido casos de violência doméstica/conjugal envolvendo relacionamentos lésbicos.

Com relação à frequência dos atendimentos de violência conjugal lésbica pelos profissionais, foi possível notar, por meio das entrevistas, que ainda que em menor frequência, algumas lésbicas têm procurado os serviços pesquisados em busca de apoio profissional. No Centro Especializado em Atendimento à Mulher (Ceam), a assistente social entrevistada afirmou: “Eu já atendi casos de mulheres lésbicas, não foi uma nem duas vezes...". No Centro de Cidadania LGBT/Niterói (CCLGBT), o assistente social relatou que também já recebeu casos: “No meu cotidiano profissional já atendi muitos casos de violência entre casais de lésbicas e de gays. Houve um que o casal se casou num mês e se separou no outro, numa separação nada amistosa".

Já no Programa SOS Mulher, a profissional destaca que não atendeu nenhum caso, ou pelo menos nenhum em que a mulher atendida relatou abertamente ter uma orientação sexual lésbica:

10 Na busca por dar visibilidade à violência praticada contra a população LGBT, foram criados os programas Brasil sem Homofobia e Rio sem Homofobia, que deram origem aos Centros da Cidadania LGBT. No entanto, tornou-se um desafio manter tais conquistas diante da conjuntura em que se encontra o cenário político brasileiro de discriminação contra LGBTs, estimulada pelo fundamentalismo religioso. Durante o processo de construção desta pesquisa, o Centro de Referência da Cidadania LGBT teve suas portas fechadas. Entretanto, como nosso objetivo era investigar a concepção dos profissionais que atendem casos de violência conjugal lésbica, foi feita uma aproximação com profissionais que já atuaram nesse Centro. 
Aqui no trabalho não [...] acho que é isso que a gente estava falando, a dificuldade que é pra trazer pra cá [...] quer dizer [...] são muros tão duros, tão engessados. Até mesmo sendo um hospital universitário que a gente pensa que tudo seria mais fácil acontecer aqui, não vem e não se torna visível aqui dentro, o que eu não consigo entender.

Pelo fato de existir uma dificuldade na obtenção de dados e no acesso à informação sobre a orientação sexual durante os atendimentos, não fica claro se esse programa não atendeu nenhum caso de violência conjugal lésbica, ou se atendeu, mas a "vítima" não se sentiu à vontade para expor sua orientação sexual.

Alguns fatores explicam o fato de haver poucos atendimentos a casos de violência conjugal lésbica nos serviços de combate à violência contra a mulher, e no caso de algumas instituições, uma escassez completa. 0 primeiro deles refere-se ao fato de que a maioria desses serviços ainda é mais direcionado às mulheres heterossexuais, por conta da violência nessas relações ocorrer com mais frequência e pela sociedade estar baseada na heterossexualidade como norma. ${ }^{11}$ Ainda que a população LGBT, e especificamente a população lésbica, venha lutando contra a discriminação e exigindo seus direitos no espaço público, a sociedade ainda apresenta grande resistência às suas demandas. Atualmente convive-se, no contexto brasileiro, com o ataque de setores conservadores aos direitos da população LGBT, apontando para a necessidade de se pensar que direito adquirido não significa necessariamente uma luta terminada; ao contrário, trata-se de um processo permeado por avanços e retrocessos.

Na fala da assistente social do Programa SOS Mulher é possível notar a preocupação pelo fato de não ter atendido nenhuma lésbica, além de um questionamento sobre para onde as lésbicas em situação de violência estão indo e se estão tendo atendimento social, psicológico e jurídico de que necessitam.

Aqui dentro é uma angústia muito grande porque [...] dentro até dos espaços onde eu atendo, eu nunca presenciei um caso de violência conjugal entre

11 Ver Petry \& Meyer, 2011. 
lésbicas [...] eu não tenho nenhum registro de mulheres nem "trans", nem lésbica. Qualquer que seja a violência, desde a física, moral, sexual, psicológica, não tenho... fora eu já vi alguns casos, nas relações informais, agora dentro de um espaço onde deveria acontecer a desconstrução disso, e as pessoas buscarem entender que aqui poderia ser acolhido e ser um espaço de acolhimento pra isso, não acontece. Esses espaços deveriam atender esses casos, e o meu desespero e a minha busca atual é isso, assim [...] já que não chega pra onde estão indo? Mas eu tenho o entendimento e o desejo porque isso passa a ser um grande desejo meu, que essas pessoas entendam que têm um lugar, e que esses lugares se transformem em um lugar de acolhimento pra essas pessoas.

Com relação às explicações sobre o porquê de as lésbicas em situação de violência conjugal e doméstica não acessarem os serviços de apoio com mais frequência, Santos (2012, p. 5) destaca que:

As intervenções institucionais e políticas em torno do tema da violência doméstica refletem uma visão heteronormativa, resultante, de resto, da tradição dos estudos sobre família e sexualidade que, até à década de 1990, se ancoravam sobretudo nas relações entre pessoas de sexo diferente. Como resultado, constata-se a invisibilidade de outras violências de gênero - incluindo a violência transfóbica e bifóbica - , bem como da violência doméstica entre pessoas do mesmo sexo.

Outra questão importante a ser destacada refere-se à dificuldade em se obter dados sobre o quantitativo de atendimentos às lésbicas envolvidas em violência conjugal em Niterói. Com relação à identificação da orientação sexual das mulheres atendidas, no caso do Ceam/Codim, o atendimento é realizado tendo como base uma ficha da Secretaria de Políticas para as Mulheres, que, segundo a profissional entrevistada, é uma ficha unificada para todos os centros de referência e nela contém a pergunta acerca do sexo do parceiro ou parceira das mulheres atendidas, o que facilita o registro dos casos. Quando questionada se as mulheres atendidas revelam ou não sua orientação sexual por ocasião do atendimento, a profissional dessa instituição relata:

Elas falam sim. Elas abrem, entendeu. Até porque na nossa ficha também tem uma pergunta que diz: "Seus parceiros sexuais são homens, só homens, 
ou homens e mulheres?". Ah não, eu gosto de meninos e meninas, eu gosto de homens e mulheres, eu gosto só de homens.

Já no Programa SOS Mulher, a profissional entrevistada manifesta uma preocupação quanto à ausência de dados e registros, mas explica que para a maioria das mulheres existe uma dificuldade em expor sua orientação sexual em um primeiro momento, por medo da exposição. De qualquer modo, o que se percebe é que mesmo com a existência de uma ficha que contemple essas informações, ela não é utilizada por todas as instituições. A subnotificação desses casos persiste. Como destaca Avena (2010, p. 101):

A violência doméstica no Brasil, principalmente entre lésbicas, é pouquíssimo documentada e não existem pesquisas e estatísticas oficiais sobre a temática. Vale ressaltar a dificuldade de realizar um levantamento destes dados, primeiramente porque não existem dados confiáveis sobre o número da população homossexual e também a crença de que este tipo de violência só aconteça entre casais heterossexuais, onde o homem é sempre o agressor.

Outra questão que é importante destacar é que na violência conjugal lésbica há uma dificuldade em delimitar quem é a agressora e quem é a agredida. Devido à construção desigual entre os gêneros masculino e feminino, e da dominação masculina, nas relações heterossexuais, na maioria dos casos em que há violência, esta é praticada pelo homem contra a mulher. No entanto, na violência conjugal lésbica, os papéis de agressora e agredida se misturam, sendo quase impossível delimitá-los claramente. Nesse sentido, surge uma questão: quem é a agressora e quem é a vítima? Ou não existe essa delimitação? Como bem destaca Soares (2012, p. 191):

Mais de quarenta anos depois de a violência doméstica ter atravessado a barreira do silêncio, a possibilidade de compreensão desse fenômeno múltiplo e complexo ultrapassa os limites de uma leitura bidimensional, fundamentada em categorias fixas como "mulher-vítima" e "homem-agressor".

A questão da violência nos relacionamentos lésbicos traz justamente a necessidade de se ampliar a leitura bidimensional do problema da 
violência conjugal e refletir sobre aspectos que desconstroem a ideia de que a violência doméstica/conjugal é um fenômeno restrito ao âmbito da heterossexualidade. Essa complexidade na definição da mulher agressora/ mulher agredida também é explicitada com bastante veemência na fala de uma das entrevistadas, quando relata que estava atendendo uma mulher lésbica que foi agredida por sua companheira e, após alguns atendimentos, essa companheira também procurou apoio no Ceam/Codim:

Então a que eu já estava atendendo eu deixei com a psicóloga, que ela já estava atendendo comigo também, e passei a atender só a suposta agressora [...]. Teve a agressão inicial, mas no decorrer... Teve uma hora (que) eu e a psicóloga a gente falava, quem é a agressora e quem não é?

Com relação a essa indefinição, Topa (2010, p. 19) destaca que:

A complexidade da dinâmica de vitimação nas relações íntimas entre mulheres é um aspecto para o qual alguns estudos chamam a atenção [...] revelando que os perpetradores de violência terão sido também vítimas em algum momento e vice-versa, sem que tal implique necessariamente abuso mútuo.

Outra dimensão a ser destacada é que esses profissionais, apesar de reconhecerem que a Lei n. 11.340/06 é aplicável às lésbicas em situação de violência, destacam um fator que muitas vezes condiciona essa aplicabilidade: as concepções - e decisões — de cada juiz:

Infelizmente, muitos juízes por conta de sua ignorância e preconceito, não permitem que a lei seja aplicada a essas pessoas. Fui a uma palestra uma vez em que um juiz disse que não aplicava a Lei Maria da Penha em casais de lésbicas porque não sabia quem era o homem da relação. (Centro de Cidadania LGBT)

É importante destacar ainda a pouca quantidade de estudos e pesquisas sobre este tema. Quando questionados sobre a importância dos estudos a respeito da violência conjugal lésbica, os profissionais entrevistados relataram opiniões variadas. Os profissionais do SOS Mulher e do Centro de Cidadania LGBT reconhecem a validade de pesquisas acadêmicas: 
Claro, muito! Sempre! Acho que os estudos e pesquisas são muito válidos e são um instrumento também de combate à violência contra a mulher. (SOS Mulher) Sim, acho extremamente válido e de suma importância estudos sobre o fenômeno da violência doméstica nos relacionamentos entre lésbicas ou gays, tendo em vista que ainda é um tabu muito grande, e principalmente porque os serviços que atendem as vítimas (saúde/polícia) ainda se baseiam no senso comum e não fazem o devido acolhimento ao problema relatado. (Centro de Cidadania LGBT)

No caso da profissional do Ceam/Codim, ela destaca que apesar de achar relevante o debate, não considera a necessidade de pesquisas específicas com relação à população lésbica, pois segundo ela, nos atendimentos deve-se enxergar a violência como um todo, independente da orientação sexual da mulher:

Eu acho que a gente tem que lidar com a violência doméstica como um todo, independente se for uma situação lésbica; eu acho que não tem que haver essa diferenciação, entendeu? Acho que quem tem que se preocupar mais um pouco com isso é o LGBT, que trabalha só nessa questão, no centro de referência LGBT [...] o que eu analiso na relação é a agressão, agora se é entre duas mulheres ou não, isso não importa muito. No meu dia a dia de atendimento, não tem que focar naquilo ou nisso, porque senão a gente começa a criar uns preconceitos e não dá conta daquilo que se propõe a fazer. Meu pano de fundo é a violência doméstica, né. A violência de gênero e a violência doméstica. Não importa de que forma que essa relação se configura. (Ceam/Codim)

No entanto, entendemos que apesar de a violência conjugal lésbica se "assemelhar" à violência ocorrida entre casais heterossexuais em alguns aspectos, ao mesmo tempo apresenta peculiaridades que exigem um esforço de reflexão para com esse fenômeno complexo, e principalmente um esforço em oferecer um atendimento de qualidade para as lésbicas em situação de violência conjugal. ${ }^{12} \mathrm{O}$ que é importante, na verdade, é pensarmos no atendimento às mulheres, pois estas não existem no singular — por isso

12 Tal questão não pode ser "compartimentada" entre instituições LGBT e "de mulheres". 
a importância de um olhar interseccional que dê conta da diversidade existente. A produção acadêmica pode ser uma aliada no reconhecimento dessa questão como uma problemática mais ampla de direitos humanos e cidadania das mulheres. Como afirma Santos (2012, p. 15):

O conhecimento acerca da violência conjugal entre mulheres é escasso. Importa obter dados estatísticos fiáveis, investigar o perfil das vítimas e das agressoras, proceder a uma tipificação da violência, aferir da hipótese da violência multilateral, identificar os catalisadores da violência e conhecer mecanismos de resolução do conflito conjugal utilizados pelas mulheres.

Nesse sentido, ao pensarmos em perspectivas de enfrentamento a esse tipo de violência, a construção de estudos e pesquisas de qualidade pode ser considerada uma importante ferramenta para combater essa questão.

Outra ferramenta que pode auxiliar no combate a esse tipo específico de violência seria maior sensibilização entre os profissionais que atendem casos de violência e até mesmo com a própria sociedade, no sentido de chamar atenção para a existência e a gravidade desse tipo de violência. Como destaca o assistente social do Centro de Cidadania LGBT:

Acho superválido fazer um trabalho de conscientização sobre violência doméstica entre casais de lésbicas e gays, tendo em vista que quanto mais informação, menor será o número de vítimas da violência em todos os sentidos (física, psicológica, patrimonial). 0 enfrentamento tem de ser diário, com campanhas em rádio, TV, nas ruas e nos trabalhos acadêmicos principalmente, tendo em vista que em muitas universidades o preconceito velado sobre o assunto faz-nos calar sobre o tema. (Centro de Cidadania LGBT)

Nesse sentido, Santos (2012, p. 20) também destaca que:

Para que medidas políticas e jurídicas inclusivas possam ter uma boa receptividade social, é imperioso investir publicamente em campanhas específicas que deem nome, rosto e voz ao tema da violência conjugal lésbica. Estas campanhas podem estar voltadas para um conjunto de intervenientes sociais, entre os quais se incluem os órgãos de comunicação social, as escolas, as 
associações de moradores, os clubes desportivos, as associações de imigrantes e as comunidades religiosas, entre outras.

Além disso, é imperioso que as instituições da rede de atendimento às mulheres em situação de violência tenham o cuidado de registrar os atendimentos realizados com as lésbicas, a fim de que a partir desses registros possam ser construídos dados quantitativos e qualitativos que possibilitem maior compreensão sobre essa problemática e seja possível pensar em formas de enfrentar essa violência.

\section{Considerações finais}

Analisar a temática da violência conjugal e doméstica nas relações lésbicas é um desafio. Trata-se de questão delicada, que nos leva a compreender a heterogeneidade da categoria mulheres e nos obriga a ampliar o olhar da violência para além do viés heteronormativo. Implica também um exercício de desconstrução que consiste em perceber que a violência doméstica possui múltiplas variações, e não se encontra restrita ao binômio homem-agressor e mulher-vítima.

A intenção ao abordar esse aspecto é chamar a atenção para a existência de uma violência ainda obscurecida nas produções acadêmicas - e no dia a dia profissional - , mas que é uma problemática real na vida de muitas mulheres. Através da análise dos dados obtidos é possível notar avanços e desafios. Por um lado, é notável o interesse e o empenho desses profissionais em compreender essa violência, ${ }^{13}$ não demonstrando resistência nem discriminação no que se refere a essa temática. Por outro lado, ao verificar o pequeno número de lésbicas atendidas nas instituições pesquisadas, evidencia-se que os serviços de atendimento, apesar de serem destinados às mulheres de maneira geral, não são atrativos para essa população específica - mesmo quando contam com profissionais sensíveis a essas questões.

13 Falamos desses profissionais especificamente, sem a pretensão de generalizar essa análise para a totalidade daqueles que lidam com essa temática. 
Defendemos a ideia de que esses serviços precisam traçar estratégias para atrair essas mulheres, como uma maneira de contribuir para uma cidadania mais ampla para as lésbicas que necessitem de apoio profissional.

O que se percebe é que mesmo essas instituições têm dificuldade para incluir a violência lésbica. $O$ que se quer enfatizar aqui é que entrevistamos uma certa "nata" dentro da rede de atendimento à mulheres e população LGBT em situação de violência. Não temos dúvida que, dependendo de outras instituições a serem entrevistadas, o resultado das entrevistas poderia ser bem diferente. Tivemos como critério entrevistar as principais instituições de atendimento na cidade. Como qualquer critério, este traz pontos positivos e negativos. Teria sido enriquecedor poder ter entrevistado outras instituições. A perspectiva de entrevistar demais profissionais não foi possível, mas aponta para o aprofundamento dessas reflexões em trabalhos posteriores.

Há também a necessidade de um trabalho de sensibilização acerca da gravidade da questão. Essa sensibilização deve ser realizada em primeiro lugar nos próprios serviços de atendimento, entre os profissionais que atendem essas mulheres; em segundo lugar entre a comunidade LGBT, que tem permanecido em silêncio quanto à existência desse tipo de violência que atinge não só lésbicas, mas também os casais gays; e por fim com a própria população lésbica, no sentido de alertar para o fato de que possui o direito de acessar as instituições da rede de atendimento e receber todo apoio social, médico, psicológico e jurídico de que necessite.

Concluindo, gostaríamos de enfatizar a importância dessa discussão no âmbito do Serviço Social. Entendemos que ainda persiste um grande distanciamento entre o Serviço Social e o debate acerca da diversidade sexual. Mas somos uma profissão que fez a opção por um projeto profissional vinculado ao processo de construção de uma nova ordem societária, como está exposto em nosso Código de Ética. Ou seja, por um exercício profissional "sem ser discriminado, nem discriminar, por questões de inserção de classe social, gênero, etnia, religião, nacionalidade, opção sexual, idade e condição física". Essa nova ordem não se faz sem a atenção para os diversos sujeitos que atendemos diariamente. 


\section{Referências bibliográficas}

AVENA, D. T. A violência doméstica nas relações lésbicas: realidades e mitos. Aurora Revista de Arte, Mídia e Política, São Paulo, n. 7, 2010.

BRASIL. Lei n. 11.340, 2006.

BRASIL. Presidência da República. Política Nacional de Enfrentamento à Violência contra as Mulheres. - Brasília: Secretaria Especial de Políticas para as Mulheres, 2011.

CFEMEA. Tolerância institucional à violência contra as mulheres. Brasília, 2014.

CORRÊA, S. O percurso global dos direitos sexuais: entre "margens" e "centros". Revista Bagoas, Natal, v. 3, n. 4, p. 17- 42, jan./jun. 2009.

GROSSI, M. P. Rimando amor e dor: reflexões sobre a violência no vínculo afetivo conjugal. In: PEDRO, Joana Maria; GROSSI, Miriam Pillar (Orgs.). Masculino, feminino, plural: gênero na interdisciplinaridade. Florianópolis: Mulheres, 2000.

PETRY, A. R.; MEYER, D. E. E. Transexualidade e heteronormatividade: algumas questões para a pesquisa. Textos \& Contextos, Porto Alegre, v. 10, n. 1, p. 193-198, jan./jul. 2011.

SANTOS, A. C. "Entre duas mulheres isso não acontece" - Um estudo exploratório sobre violência conjugal lésbica. Revista Crítica de Ciências Sociais, Coimbra, n. 98, p. 3-24, 2012.

SOARES, B. M. A “conflitualidade" conjugal e o paradigma da violência contra a mulher, Dilemas - Revista de Estudos de Conflito e Controle Social, Rio de Janeiro, v. 5, n. 2, p. 191-210, abr./maio/jun. 2012.

TOPA, H. No arco-íris também há roxo: violência conjugal nas relações lésbicas". LES Online, v. 2, n. 1, 2010.

VICKERS, L. The second closet: domestic violence in lesbian and gay relationships - a Western Australian perspective, e Law Journal: Murdoch University Electronic Journal of Law, Austrália, 1996.

\section{Sobre os autores}

Nathalî̂ CRISto Ribeiro dos SANTOS - Doutoranda em Estudos pós-graduados em política social.

E-mail: nathaliecristo@hotmail.com

Rita Freitas - Professora titular do Programa de Estudos pós-graduados.

E-mail: ritacsfreitas@uol.com.br

Glauber lucas Ceara-Silva - Doutorando em Estudos pós-graduados em Política Social (Bolsista Capes).

E-mail: gllucesi@gmail.com 